\title{
Effects of two bisbenzylisoquinoline alkaloids, Antioquine and Tetrandrine, compared to Verapamil in Rat Thoracic Aorta
}

\author{
JOSÉ L. MARTINEZ ${ }^{1}$, JULIO BENITES ${ }^{2}$, HAROLD GOMEZ ${ }^{3}$, SILVIA VARGAS- \\ RUEDA $^{4}$, RAÚL VINET ${ }^{5,6}$, LUISAURIS JAIMES ${ }^{7}$ and CLAUDIO LAURIDO ${ }^{7 *}$ \\ ${ }^{1}$ Vicerrectoría de Investigación, Desarrollo e Innovación, Universidad de Santiago de Chile, Avenida Libertador \\ Bernardo O’Higgins, 3363, Estación Central, Of. 325, Casa Central, Codigo Postal 9160000, Santiago, Chile \\ ${ }^{2}$ Facultad de Ciencias de la Salud, Universidad Arturo Prat, Avenida Arturo Prat, 2120, Codigo Postal 1100000, Iquique, Chile \\ ${ }^{3}$ Facultad de Ciencias Farmacéuticas, Universidad de Cartagena, Cl 6 \# 3"N, Cartagena, Bolívar, Colombia \\ ${ }^{4}$ Facultad de Química Ambiental, Universidad Santo Tomas, Cl 197 \# 180-385, \\ Autopista Floridablanca, Floridablanca, Santander, Colombia \\ ${ }^{5}$ Facultad de Farmacia, Universidad de Valparaíso, Avenida Gran Bretaña, 1093, 2360102 Valparaíso, Chile \\ ${ }^{6}$ Regional Center for the Study in Foods and Health/CREAS, Avenida Universidad, 330, 2362696 Valparaíso, Chile \\ ${ }^{7}$ Facultad de Química y Biología, Universidad de Santiago de Chile, Avenida Libertador Bernardo \\ O’Higgins, 3363, Estación Central, Codigo Postal 9160000 Santiago, Chile
}

Manuscript received on August 5, 2017; accepted for publication on October 15, 2017

\begin{abstract}
The objective of this study was to compare two alkaloids (antioquine and tetrandrine) with verapamil; knowing that the smooth muscle respond to $\mathrm{KCl}$ and relationships with calcium. The effects of antioquine and tetrandrine, was studied in adults Wistar rat with modified methods used in the determination of aorta contractility and compared with verapamil effect in the same assays. The analysis of the effect of a drug or extract on aortic reactivity included maximal relaxation or maximal contraction (Cmax) (Phase 1). In our results, verapamil induced a blockade of $98.7 \pm 0.7 \%(n=6)$ in presence of endothelium and $97.9 \pm 4.3 \%$ in ausence of endothelium, both in phase 1 and in phase 2 of $47.4 \pm 4.1 \%(n=6)$ in aortas in the presence of endothelium and $61.8 \pm 1.1 \%$ in ausence of endothelium; Tetrandrine assays showed a phase 1 blocking effect of $63.4 \pm 5.5$ and $47.7 \pm 2.9 \%$ (with and without endothelium, respectively) and phase 2 of $43.5 \pm$ 6.2 and $28.5 \pm 5.7 \%$, (with and without endothelium, respectively). Antioquine presents in phase 1 and phase 2, a blockade that is not significant from the point of view of calcium antagonism. We can conclude that tetrandrine block the movement of calcium from both intracellular and extracellular deposits, with the greatest effect when aortas are in the presence of endothelium.
\end{abstract}

Key words: antioquine, tetrandrine, verapamil, calcium antagonism, rat thoracic aorta.

\section{INTRODUCTION}

Antioquine (ANT) and Tetrandrine (TET), are

Correspondence to: José Luis Martinez

E-mail: joseluis.martinez@usach.cl

"In memoriam bisbenzylisoquinoline alkaloids; TET was isolated from Chinese Stephania tetrandra S Moore (D'ocon et al. 1989), a traditional medicine herb, and ANT isolated from the Colombian plant, Pseudoxandra sclerocarpa Maas (Prieto et al. 2015). 
The cardiovascular pharmacological effects and the mechanism of action of this compound were reviewed. According to important studies, TET (Figure 1) exhibits antiarrhythmic action in several experimental arrhythmic models (Cheng and Qian 1989, Qian et al. 1983); antihypertensive effect (Fang and Jiang 1986a), in spontaneously hypertensive rats, renal hypertensive rats and in Doca-salt hypertensive rats (Fang and Jiang, 1986a), The antihypertensive effects of TET have been demonstrated in both experimental hypertensive animals and in patients (Huang et al. 2016). Recent studies showed that in addition to its calcium antagonistic effect, TET interacts with $M$ receptors. Modulation by $\mathrm{M}$ receptor is one of the pharmacological mechanisms of the cardiovascular effects of TET. In addition, it has been demonstrated that TET is a calcium antagonist (D'ocon et al. 1989, Fang and Jiang 1986b); not being a selective calcium channel blocker in vascular smooth muscle (Kwan et al. 1992). The mechanism of action of TET has been extensively explored, for instance, TET could inhibit both $\mathrm{T}$ and $\mathrm{L}$ type calcium channels currents in ventricular cells (Liu et al. 1992); and block voltage-dependent $\mathrm{Ca}^{2+}$ and $\mathrm{Ca}^{2+}$ activated $\mathrm{K}^{+}$channels (Wang and Lemos 1995).

ANT (Figure 2) was also studied as a calcium antagonist (Prieto et al. 2015). In aorta, the mechanisms involved in contractions following receptor by $\mathrm{Ca}^{2+}$-mobilization agonist follow at three major components: $\mathrm{Ca}^{2+}$ influx, intracelular $\mathrm{Ca}^{2+}$ release and an increase in $\mathrm{Ca}^{2+}$ sensitivity of the contractile elements (Karaki et al. 1997).

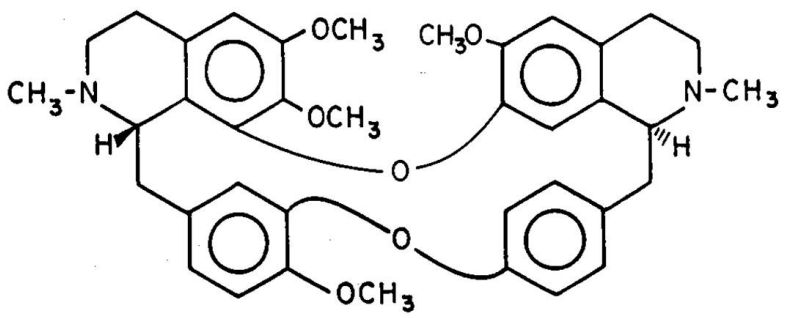

Figure 1 - Tetrandrine, isolated from Stephania tetrandra $\mathrm{S}$ Moore.
In this work, knowing that the smooth muscle respond to $\mathrm{KCl}\left(\mathrm{K}^{+}\right)$with an early rapid phasic contraction followed by a more slowly developing, but with a sustained tonic contraction (Högestätt and Anderson 1984, Marriott 1989), the effects of ANT, TET and verapamil, (the latter was known as a calcium antagonist) was performed and compared in isolated aortic ring of rats. The study was conducted in the depolarization with $\mathrm{K}^{+}$at 70 $\mathrm{mM}$, and is dependent of intra and extracellular calcium (Karaki et al. 1997).

\section{MATERIALS AND METHODS}

\section{GENERAL}

Reagents for measuring aorta contractibility and isometric tensions: $\mathrm{NaCl}, \mathrm{KCl}, \mathrm{NaHCO}_{3}, \mathrm{KH}_{2} \mathrm{PO}_{4}$, $\mathrm{MgCl}_{2}, \mathrm{CaCl}_{2}$, glucose and EDTA were purchased form Sigma (USA). For testing the integrity of the epithelium, acetylcholine and phenylephrine were used (both were purchased from Sigma Aldrich Co. (USA).

\section{ANIMALS}

Adults Wistar rats of both sexes weighing $300-$ $450 \mathrm{~g}$, (intact, $\mathrm{n}=6$ ), were used in this study in accordance with the Guide for the Care and Use of Laboratory Animals (1985), NIH, Bethesda, USA 2011, and the University of Santiago of Chile Ethical Committee. Rats were allowed to water and food ad libitum, and placed in cage with controlled temperature $\left(25 \pm 1^{\circ} \mathrm{C}\right)$ and with a dark-light cycle of 12/12 hours, starting at 8 a.m.

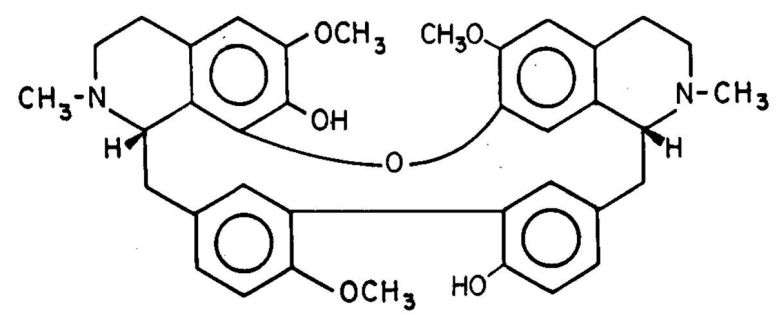

Figure 2 - Antioquine, isolated from Pseudoxandra esclerocarpa Maas. 


\section{AORTA CONTRACTIBILITY MEASUREMENTS}

A modified method (Illanes et al. 1993, Vinet et al. 2016) was used in the determination of aorta contractility as follows: the thoracic aorta was carefully excised and placed in a Petri dish containing Krebs-Henseleit modified buffer (in mM: $\mathrm{NaCl} 122 ; \mathrm{KCl} 4.7 ; \mathrm{NaHCO}_{3} 15.5 ; \mathrm{KH}_{2} \mathrm{PO}_{4}$ 1.2; $\mathrm{MgCl}_{2}$ 1.2; $\mathrm{CaCl}_{2}$ 2.0; glucose 11.5; EDTA $0.026 ; \mathrm{pH} 7.4)$ at room temperature. The aorta is then dissected, cleaned of connective tissue and divided into $5 \mathrm{~mm}$ rings segments. The rings are suspended between two L shaped stainless steel hooks and placed in a 20-30 mL organ chambers containing modified Krebs-Henseleit buffer, maintained at $37{ }^{\circ} \mathrm{C}$ and oxygenated continuously with a $95 \% \mathrm{O}_{2}-5 \% \mathrm{CO}_{2}$ gas.

\section{ISOMETRIC TENSION MEASUREMENTS}

Isometric tensions are measured using a force displacement transducer connected to a polygraph. The rings are allowed to equilibrate in the tissue bath for 60 min under an optimal resting tension of $1.5 \mathrm{~g}$. Rings are progressively stretched at least three times with a depolarizing $70 \mathrm{mM} \mathrm{KCl}$ solution (in mM: $\mathrm{NaCl} 52 ; \mathrm{KCl} 70.0 ; \mathrm{NaHCO}_{3}$ 15.5; $\mathrm{KH}_{2} \mathrm{PO}_{4} 1.2 ; \mathrm{MgCl}_{2} 1.2 ; \mathrm{CaCl}_{2} 2.0$; glucose 11.5; EDTA 0.026; $\mathrm{pH} 7.4$ ) until the contractile response is maximal (optimal and reference tension). Aortic rings are repeatedly washed and allowed to re-equilibrate for an additional $30 \mathrm{~min}$. The preparation is ready to evaluate relaxation or contraction activities.

\section{ANALYSIS OF THE EFFECT OF A DRUG AND INTEGRITY OF THE ENDOTHELIUM}

The analysis of the effect of a drug or extract on aortic reactivity (Martinez et al. 2017) included maximal relaxation or maximal contraction (Cmax) (Phase 1) (Martinez et al. 2013). Integrity of endothelium may be assessed by testing the relaxation produced by the addition of acetylcholine $(1 \mu \mathrm{M})$ in phenylephrine (PE), (0.1-1 $\mu \mathrm{M})$ precontracted rings. Response is measured as a percentage of relaxation from the precontracted level, considering the baseline as $100 \%$ relaxation (Vinet et al. 2012).

When the contraction is evaluated, drug or extract is added directly on aortic rings under basal tension by cumulative addition to obtain a concentration-response curve. Rings were repeatedly washed and allowed to equilibrate for an additional $30 \mathrm{~min}$ before testing the extracts. Subsequently, rings were precontracted with PE $(0.1 \mu \mathrm{M})$ and once a stable contraction was achieved, cumulative concentration-response curves were obtained by a stepwise increase in the extract concentration.

\section{DATA PROCESSING}

Data obtained from vascular reactivity studies were expressed as means \pm SEM. Analysis of variance (ANOVA) followed by a Tukey test to evaluate the statistical significance of vascular reactivity results. All these analyses were carried out analysis by using the GB-STAT 3.0 program. Differences were considered significant with probability values less than 0.05 .

\section{RESULTS AND DISCUSSION}

Smooth muscle responds to potassium chloride $\left(\mathrm{K}^{+}\right)$with an early rapid-phase contraction followed by a more slowly developing, but sustained tonic contraction (Bolton 1979, Rodger 1985). Contractions in response to $\mathrm{K}^{+}$are the result of increased membrane permeability to calcium $\left(\mathrm{Ca}^{2+}\right)$ consequent to membrane depolarization, that can be directly or by the release from endogenous neurotransmitters. It is generally accepted that in smooth muscle, mobilization of $\mathrm{Ca}^{2+}$ from extracellular or intracellular sources is necessary to support contraction (Karaki et al. 1997, Webb 2003).

Mechanisms involved in contractions following receptor stimulation by $\mathrm{Ca}^{2+}$-mobilization agonists are far more complex than those by following simple membrane depolarization in vascular smooth muscle; there are at least three major 
components: $\mathrm{Ca}^{2+}$ influx, intracellular $\mathrm{Ca}^{2+}$ release and an increase in $\mathrm{Ca}^{2+}$ sensitivity of the contractile elements (Baba et al. 1985). The contraction induced by $\mathrm{KCl}$, prostaglandin $\mathrm{F}_{2 \alpha}$, oxytocin, methacholine or $\mathrm{CaCl}_{2}$ depends on the entry of extracellular calcium in smooth muscle, and are solely dependent on the verapamil-sensitive influx of $\mathrm{Ca}^{2+}$ (Karaki et al. 1997, Al Otaibi 2014, Albert and Large 2003, Matthew et al. 2004).

In our results, verapamil induced a blockade of $98.7 \pm 0.7 \%(n=6)$ of phase 1 and in phase 2 of $47.4 \pm 4.1 \%(n=6)$ in aortas in the presence of endothelium; While in the absence of endothelium the percentages correspond to $97.9 \pm 4.3$ (Table I), and $61.8 \pm 1.1 \%$ (Table II), respectively, for phase 1 and 2, ( $n=6$ in both cases). From these results it is clear that Verapamil in our preparation produces complete phase 1 (Table I) blockade being independent of the presence of endothelium; Not so in phase 2 where there is a slightly significant difference dependent on endothelium.

TET assays showed a phase 1 blocking effect of $63.4 \pm 5.5$ and $47.7 \pm 2.9 \%$ (with and without endothelium, respectively) and in phase 2 (Table II) of $43.5 \pm 6.2$ and $28.5 \pm 5.7 \%$, respectively. In this case, the results would indicate no endothelium dependence and that calcium blockade would be of the same caliber for both phases (in all cases $n$ $=6$ ). ANT presents in phase 1 a blockade that is not significant to some extent with TET whereas in phase 2 the blockade does not have a significant difference, which would indicate that possibly its mechanism of action is different.

The search for new anti-hypertensive natural compounds is an interesting field of research. High blood pressure is a global problem causing thousands of deaths or permanent disabilities. TET, a bisbenzylisoquinoline (BBQ) alkaloid isolated from the Chinese plant Stephania tetrandra, has been characterized as a calcium antagonist of natural origin and $\mathrm{a} \mathrm{Ca}^{2+}$ voltage-dependent channel blocker (D'ocon et al. 1989, Fang and Jiang 1986b,
TABLE I

It shows the three compounds studied (tetrandrine, antioquine and verapamil) in rat aorta with (presence of endothelium) and without (absence of endothelium) in phase 1 of the contraction. The effect of tetrandrine and antioquine is is significantly different but the blocking effect of verapamil is almost total.

\begin{tabular}{cccc}
\hline Compound & $\begin{array}{c}\text { With } \\
\text { endothelium }\end{array}$ & $\begin{array}{c}\text { Without } \\
\text { endothelium }\end{array}$ & n \\
\hline Verapamil & $98.7 \pm 0.7$ & $97.9 \pm 4.3$ & 6 \\
Antioquine & $43.6 \pm 5.1$ & $38.2 \pm 3.7$ & 6 \\
Tetrandrine & $63.4 \pm 5.5$ & $47.7 \pm 2.9$ & 6 \\
\hline
\end{tabular}

TABLE II

It shows the three compounds studied (tetrandrine, antioquine and verapamil) in rat aorta with (presence of endothelium) and without (absence of endothelium) in phase 2 of the contraction. The blocking effect of verapamil compared to tetrandrine in the presence of endotelium is similar (there is no significant difference) but it is significative in the absence of endothelium, but with a lower tetrandrine blockade.

\begin{tabular}{cccc}
\hline Compound & $\begin{array}{c}\text { With } \\
\text { endothelium }\end{array}$ & $\begin{array}{c}\text { Without } \\
\text { endothelium }\end{array}$ & n \\
\hline Verapamil & $47.4 \pm 4.1$ & $61.8 \pm 1.1$ & 6 \\
Antioquine & $16.0 \pm 4.4$ & $9.1 \pm 1.6$ & 6 \\
Tetrandrine & $43.5 \pm 6.2$ & $28.5 \pm 5.7$ & 6 \\
\hline
\end{tabular}

Kwan et al. 1992). Also, ANT, BBQ isolated from the Colombian plant Pseudoxandra sclerocarpa, shows a similar effect to diltiazem (Prieto et al. 2015). Experiments with rat thoracic aortas in vitro of Wistar rat were used in this study. After depolarized with $\mathrm{KCl}$, a maximum contractioncalcium dependent occurs in two phases, assayed for TET and ANT, using verapamil as control. The resulting effects on phases 1 and 2 (Tables I and II): in phase 1 with endothelium, ANT showed a blockage of $43.6 \pm 5.1 \%$ compared with verapamil and TET; $38.2 \pm 3.7 \%$ for phase 1 in absence of endothelium. For phase 2 (Table II), ANT reduces in $16 \pm 4.4 \%$ in presence of endothelium and $9.1 \pm$ $1.6 \%$ in absence of endothelium, both compared to verapamil and TET.

We can conclude that these compounds block the movement of calcium from both intracellular 
and extracellular deposits, with the greatest effect when aortas are in the presence of endothelium. The development of new anti hypertensive drugs using these compounds could become a reality if pursued further investigation.

\section{ACKNOWLEDGMENTS}

Funded by DICYT number 021643MS (JLM).

\section{REFERENCES}

AL OTAIBI M. 2014. The physiological mechanism of uterine contraction with emphasis on calcium ion. Calc Sign 1: 70-75.

ALBERT A AND LARGE W. 2003. Store-operated $\mathrm{Ca}^{2+}$ permeable non-selective cation channels in smooth muscle cells. Cell calcium 33: 345-356.

BABA K, KAWANISHI M, SATAKE T AND TOMITA T. 1985. Effects of verapamil on the contractions of guineapig tracheal muscle induced by $\mathrm{Ca}, \mathrm{Sr}$ and $\mathrm{Ba}$. $\mathrm{Br} \mathrm{J}$ Pharmacol 84: 203-211.

BOLTON TB. 1979. Mechanism of action of transmitters and other substances on smooth muscle. Physiol Rev 59: 606718.

CHENG JH AND QIAN JQ. 1989. Effects of quinidine, dauricine and tetrandrine on reperfus ion-induced arrhythmia in the rats. Chin Pharmacol Bull 5: 151-153.

D'OCON MP, CANDENAS ML, ANSELMI E, ZAFRAPOLO MC AND CORTES D. 1989. Antioquine: a new bisbenzylisoquinoline alkaloid with calcium antagonist activity. Arch Int Pharmacodyn Thér 297: 205-216.

FANG DC AND JIANG MX. 1986a. A new calcium antagonist of Chinese medicine origin:Tetrandrine. J Hypertension 4: 150-152.

FANG DC AND JIANG MX. 1986b. Studies on tetrandrine calcium antagonistic action. Chin Med J 99: 638-644.

HÖGESTÄTT E AND ANDERSON KE. 1984. Mechanism behind the biphasic contractile response to potassium depolarization in isolated rat cerebral arteries. J Pharmacol Exp Ther 228: 187-195.

HUANG YL ET AL. 2016. Tetrandrine, an alkaloid from $S$. tetrandra exhibits anti-hypertensive and sleep-enhancing effects in SHR via different mechanisms. Phytomedicine 23: $1821-1829$.

ILLANES AG, PENNA M AND MARTINEZ JL. 1993. Vascular relaxing factor released by isolated rat atria its effect in rat isolated aorta. Gen Pharmac 24: 315-320.

KARAKI H, OZAKI H, HORI M, MITSUI-SAITO M, AMANO K, HARADA K, MIYAMOTO S, NAKAZAWA
H, WON K AND SATO K. 1997. Cacium movements, distribution, and functions in smoth muscle. Pharmacol Rev 49: 158-230.

KWAN CY, DENG HW AND GUAN YY. 1992. Tetrandrine is not a selective calcium channel blocker in vascular smooth muscle. Acta Pharmacol Sin 13: 385-390.

LIU QY, KARPINSKI E AND PANG PKT. 1992. Tetrandrine inhibits both $\mathrm{T}$ and $\mathrm{L}$ calcium channels currents in ventricular cells. J Cardiovasc Pharmacol 20: 513-519.

MARRIOTT JF. 1989. The effects of verapamil upon noradrenaline-induced contraction of the rat isolated aorta following acute and prolonged alterations in $\mathrm{PO}_{2}$. $\mathrm{Br} \mathrm{J}$ Pharmacol 98: 1101-1108.

MARTINEZ JL, ROVIROSA J, LAURIDO C, SAN-MARTIN A, VINET R AND JAIMES L. 2017. The pulmonate limpet Siphonaria lessoni: Pharmacological study of norsiphonarienone, a polipropionate. Pak Vet J 37: 482484.

MARTINEZ JL, ZAMORANO B, BRUZZONE ME, VINET R AND LAURIDO C. 2013. Are alteration in $\mathrm{KCl}$ inducedcontraction of thoracic aortic rings of ovariectomized rats dependent on calcium metabolism? Contrib Científ Tecnol 138: 34-38.

MATTHEW A, SHMYGOL A AND WRAY S. 2004. Ca ${ }^{2+}$ entry, efflux and release in smooth muscle. Biol Res 37: 617-624.

PRIETO J, CORTES D, JAIMES L, LAURIDO C, VINET R AND MARTÍNEZ JL. 2015. Pseudoxandra sclerocarpa Maas, Colombian medicinal plant: a review. Bol Latinoam Caribe Plant Med Aromat 14: 308-316.

QIAN JQ, THOOLEN MJMC, VAN MEEL JCA, TIMMERMANS PBMWM AND VAN ZWIETEN PA. 1983. Hypotensive activity of tetrandrine in rats: investigation into its mode of action. Pharmcology 26: 187-197.

RODGER IW. 1985. Excitation-contraction coupling and uncoupling in airway smooth muscle. Br J Clin Pharmacol 20: 255S-266S.

VINET R, ALVAREZ R, KNOX M, GUZMAN L, MARTINEZ JL AND FLORES E. 2016. Vasodilatory properties of Solanum crispum Ruiz \& Pav. a South American native plant. Bol Latinoam Caribe Plant Med Aromat 15: 94-98.

VINET R, KNOX M, MASCHER D, PAREDES-CARBAJAL C AND MARTINEZ JL. 2012. Isolated aorta model and its contribution to phytopharmacology. Bol Latinoam Caribe Plant Med Aromat 11: 35-45.

WANG G AND LEMOS JR. 1995. Tetrandrine: a new ligand to block voltage-dependent $\mathrm{Ca}^{2+}$ and $\mathrm{Ca}^{2+}$ activated $\mathrm{K}^{+}$ channels. Life Sci 56: 295-306.

WEBB RC. 2003. Smooth muscle contraction and relaxation. Adv Physiol Educ 7: 201-206. 